\title{
The Secrets to Better Athletic Performance
}

\author{
Mesut Cerit* \\ Faculty of Sport Science, Lokman Hekim University, Türkey \\ *Corresponding author: Mesut Cerit, Faculty of Sport Science, Lokman Hekim University, Ankara, Türkey
}

\begin{tabular}{|c|c|}
\hline ARTICLE INFO & ABSTRACT \\
\hline Received: 幽 January 17, 2020 & Citation: Mesut Cerit. The Secrets to Better Athletic Performance. Biomed J Sci \& Tech \\
\hline Published: 蕾 January 27, 2020 & Res 25(1)-2020. BJSTR. MS.ID.004132. \\
\hline
\end{tabular}

\section{Short Communication}

Genetic contributions to athletic performance are remarkably complex with unique gene-environment interactions specific to each athlete, including effects on physiological, motor and psychological characteristics. Athletic ability is an exceptional performance that is partly innate, relatively site-specific, found only in a limited minority of individuals and can be described in part at an early stage of development. More importantly, significant aspect of athletic ability is the idea that early signs of abilities provide a basis for predicting future success. The contribution of genetics in the development of athletic performance is an undeniable fact. The characteristics encoded in DNA sequences or strands that cause differences between individuals also determine the limits of athletic performance. Genetic advantages allow elite athletes to perform at a high level of physical performance. In addition to environmental factors, lifestyle and motivation for the development of athletic performance at the highest level, the correct sequence of genetic variables makes it easier to achieve peak performance [1-3]. Many champions have the same gene type at the Olympic level, indicating the significance of choosing the right genotype for success at elite level [4].

It may be possible to define the performance pool of individuals through genes such as angiotension converting enzyme (ACE) and alfa-actinin-3 (ACTN3), which have great effects on training and physical performance development. One of the details needs to be contemplated in workout planning is that training loads be determined by taking into consideration the dominant energy systems which are suitable for the athletes genetic structure and the type of the sport's discipline. Genomic determinants of the responses or effects of various phenotypes to regular exercise will enable strengthening training application protocols where skilled athletes can perform high [3]. Genetic codes have determined how the body will take shape, physical performance limits, anatomical structure and physiological characteristics from the moment the womb starts (early stages of embryo formation).Gene-induced behaviors affect fitness level, exercise adaptation, calorie consumed during activities, and type of diet. Genetic differences can reach some of their goals in a very short period of time, while others can achieve high performance over a long period of time. The quality of the training workouts and the increasing number of the exercise make it easier to achieve the goal. Genetic differences are the basis for the success of some 3000 hours of training and some 10,000 hours of training for the improvement of athletic performance [5]. Genes are the source of functional behaviors that are shaped as a result of the alteration of organism transferred from generation to generation under the influence of lifestyle and environmental factors. These small changes, which are transferred from generation to generation, constitute differences between individuals [6,7].

Differences between humans are not limited to skin color and body shape; the living environment and climate are also very effective in the formation of these differences. These differences in human phenotypes result from the interaction of genetic variation with environmental stimuli. Elite athletes are examples of the interactions of genomic and epigenomic properties, training practices, and changes in nutrition, lifestyle and environmental factors. Muscle remodeling and adaptation based on genetic adaptation and usage patterns is the best example of the ability to react to and adapt to the environment. Researchers are trying to understand the adaptation of the muscles to the stimuli and how the muscles work under different conditions and how skeletal muscle structures and properties change through evolution [8]. The genetic inheritance that triggers athletic success, environmental factors and the character of exercise loads applied in the personal lifestyle, neuromotor development, and cultural differences can reveal individual variations or differences. Considering all these 
variables, performance improvement and follow-up and control of the athletic success chart may become more predictable. Learning individual genotype characteristics can be a useful and usable tool for creating individual-oriented training programs and recognizing individuals with genetic potential to become elite athletes, enabling the athlete to orientate in a harmonious direction and to the right disciplines. In addition, this information also gives coaches the opportunity to assist them by providing guidance, while allowing active athletes to overcome their physiological weakness in the best way and designing their personal training programs according to the physiological characteristics of the athlete.

It is very important to carefully reflect the findings of the research and the relationship between genetic and athletic performance to the world of sports. Studies to date have mostly focused on identifying genes underlying physiological characteristics that make up athletic performance. Defining the role of psychological factors in performance is an ongoing challenge for sports science researchers and it is unclear how necessary these factors are due to their complexity [9]. As a result, athletic performance is an enormously complex and multi-faceted phenomenon, and is determined by numerous factors such as genetics (proportion of muscle fiber type, aerobic and anaerobic power and capacity and adaptation to training), psychological and social factors, physical condition, knowledge and experience of the trainer, talent of the athlete and well planning as well as by the interaction among them [10]. These changes and all the variables to be taken into consideration will enable us to make healthy predictions about performance development and sporting success. The point is not the types of the genes but the way you trigger them is all that matters.

\section{Acknowledgement}

None.

\section{ISSN: 2574-1241}

DOI: $10.26717 /$ BJSTR.2020.25.004132

Mesut Cerit. Biomed J Sci \& Tech Res

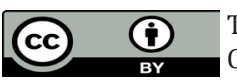

This work is licensed under Creative Commons Attribution 4.0 License

Submission Link: https://biomedres.us/submit-manuscript.php

\section{Conflict of Interest}

No conflict of interest.

\section{References}

1. Pitsiladis Y, Wang G, Wolfarth B (2011) Genomics of aerobic capacity and endurance performance: clinical implications In Pescatello LS and Roth SM (Eds.)., Exercise Genomics. Molecular and Translational Medicine Series. Humana Press, New York, USA, pp. 179-230.

2. Lisa M, Guth V, Stephen M Roth (2013) Genetic Influence on Athletic Performance. Curr Opin Pediatr 25(6): 653-658.

3. Cerit M (2018) Hypothetical approach to the location of genotypes (ACE \& ACTN3) associated with energy system for the athletic performance. Journal of Sport Science Researches 3(1): 97- 105.

4. Papadimitriou Alejandro Lucia, Nir Eynon (2016) ACTN3 R577X and ACEI/D gene variants influence performance in elite sprinters: a multicohort study. BMC Genomics 17: 285.

5. Cerit M, Cakıroğlu T (2019) Athletic Performance and Genetics. TURANCSR International Scientific, Peer-Reviewed and Refereed Journal 11(43): 1309-4033.

6. Montgomery HE, Clarkson P, Bernard M, Bell J, Brynes A, et al. (1999) Angiotensin-converting-enzyme gene insertion/deletion polymorphism and response to physical training. Lancet 353(9152): 541-545.

7. Cerit M, Çolakoğlu M, Erdoğan M, Berdeli A, Cam FS (2006) Relationship between ACE genotype and short

8. Bouchard C, Hoffman E (2011) Genetic and Molecular Aspects of Sport Performance. Volume XVIII of the Encyclopaedia of Sports Medicine an IOC Medical Commision Publication.

9. Davids K, Baker J (2007) Genes, environment and sport performance: Why the nature-nurture dualism is no longer relevant. Sports Medicine 37: 961-980.

10. Cerit M, Erdoğan M (2018) Evaluation Of The Soldier's Physical Fitness Test Results (Strength Endurance) In Relation To ACE Genotype. International Journal of Sport Sciences and Health. UDC, 616056.7:355.11(560).

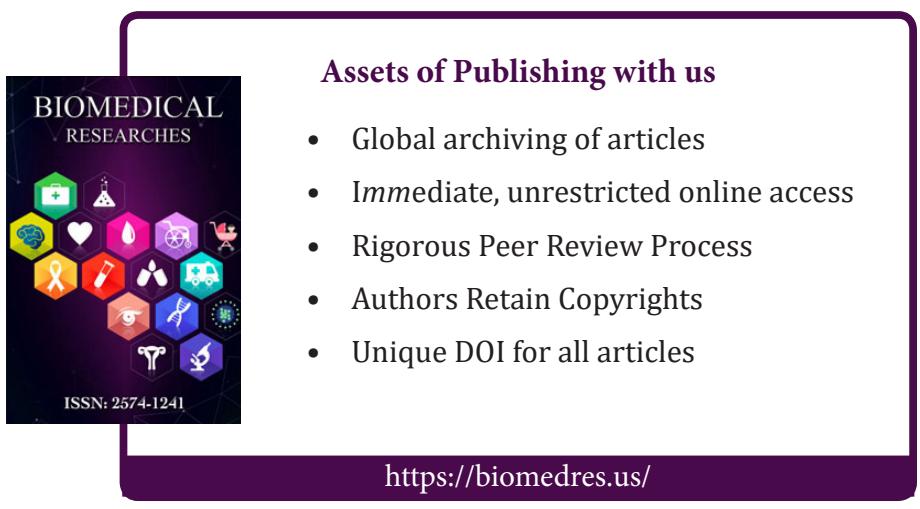

Copyright@ Mesut Cerit | Biomed J Sci \& Tech Res | BJSTR. MS.ID.004132. 